\section{RSP}

http://www.rsp.fsp.usp.br/
Revista de Saúde Pública

\title{
Challenges and lessons from a primary care intervention in a Brazilian municipality
}

\author{
Mônica V Andrade' (iD, Kenya Noronha' (iD, Clareci S Cardoso" iD, Claudia D L Oliveira" \\ Júlia A Calazans"'I ID, Michelle N Souza"' ip \\ I Universidade Federal de Minas Gerais. Departamento de Economia. Centro de Desenvolvimento e \\ Planejamento Regional. Belo Horizonte, MG, Brasil \\ " Universidade Federal de São João del-Rei. Campus Centro-Oeste. Departamento de Saúde Coletiva. \\ Divinópolis, MG, Brasil \\ III Universidade Federal de Minas Gerais. Departamento de Demografia. Centro de Desenvolvimento e \\ Planejamento Regional. Belo Horizonte, MG, Brasil
}

\section{Correspondence: \\ Mônica V Andrade \\ Centro de Desenvolvimento e Planejamento Regional (CEDEPLAR) Faculdade de Ciências Econômicas- UFMG \\ Av. Antônio Carlos, 6627 Pampulha 31270-901 Belo Horizonte, MG, Brasil \\ E-mail: mviegas123@gmail.com}

Received: Jul 31, 2017

Approved: Dec 1, 2017

How to cite: Andrade MV Noronha K, Cardoso CS, Oliveira CDL, Calazans JA, Souza MN. Challenges and lessons from a primary care intervention in a Brazilian municipality. Rev Saude Publica. 2019;53:45.

Copyright: This is an open-access article distributed under the terms of the Creative Commons Attribution License, which permits unrestricted use, distribution, and reproduction in any medium, provided that the original author and source are credited.

\section{ABSTRACT}

OBJECTIVE: To address the implementation of the Lab for Innovation in Chronic Conditions in Santo Antonio do Monte, indicating the main challenges and lessons of a new chronic condition model.

METHODS: This is an observational study based on two sources of data: 1) two cross-sectional household surveys, 2013 (2012 as reference year) and 2015 (2014 as reference year), representative for the entire population and four target groups (pregnant women; children under two years old; individuals with hypertension and diabetes); medical records of individuals who self-reported having hypertension or diabetes in the household survey of 2013. A descriptive statistics analysis was performed.

RESULTS: The main findings showed that the public health system is the main provider of health services, mainly primary care, in Santo Antonio do Monte. Besides, the implementation of Lab for Innovation in Chronic Conditions showed the importance of building a Primary Health Care network in small municipalities.

CONCLUSIONS: Community health agents and health managers played a fundamental role in the Primary Health Care network. The case study of Santo Antonio do Monte poses some challenges and lessons that clarify future interventions on building a Primary Health Care network that is essential to provide an adequate and longitudinal care to chronic conditions.

DESCRIPTORS: Chronic Disease, prevention \& control. Community Health Workers. Community Health Services. Health Care Levels. 


\section{INTRODUCTION}

After the Brazilian Unified Health System (SUS) was created, in 1988, several policies have been implemented to consolidate a universal health coverage in Brazil ${ }^{1-3}$. SUS is a public decentralized system in which municipalities and states manage and provide health services. Given their knowledge about the population's needs, their main role is to organize primary health care (PHC).

In 2010, Brazil had 5,565 municipalities, $70 \%$ of them had less than 20,000 inhabitants 4 . The small population size associated with low levels of gross domestic product per capita (GDP) raises challenges for the organization and delivery of PHC at the municipal level. In 1994, the federal government implemented the Family Health Strategy (FHS ${ }^{2}$ to consolidate PHC. FHS is a geographically and community-based program that strengthens the relationship between providers and patients. It represented an important change in the public healthcare model when it shifted from a curative to a preventive care ${ }^{5-7}$. According to this strategy, families are the focus of public health policies that should cover primary care for all population groups. The Family Health Teams (FHT) are composed of a family physician, a nurse, a nursing assistant and at least 4-12 community health agents (CHA). CHA are recruited because they can easily identify the local needs of the population. They must be able to detect symptoms of diseases, to refer individuals to the care needed and identify the need for continued care, acting as the bridge between community and public health system ${ }^{8-10}$. Empirical evidence has already been raised about the recent improvements observed in the population health status and access to healthcare due to FHS coverage $e^{3,8,11-14}$.

In Brazil, the burden of chronic conditions due to the aging process and unhealthy life-style has increased ${ }^{15}$. It is noteworthy that chronic conditions refer to a broader concept than only the presence of chronic diseases. They can be defined as health conditions that persist over time and require ongoing management. This approach classifies persistent communicable diseases (e.g. HIV/AIDS and tuberculosis), mental disorders and impairments as chronic condition $\mathrm{s}^{16}$. Mendes ${ }^{17}$ has expanded this concept by considering maternity and perinatal health care needs related to life cycles, such as child, adolescent and elderly care. Therefore, the creation of a network that includes primary, secondary and tertiary health services is fundamental to provide an integral and longitudinal healthcare. The traditional model targeted to acute conditions is not able to sustain satisfactory health outcomes when they have to deal with chronic conditions ${ }^{18}$.

The Brazilian Ministry of Health has already recognized these caveats and launched SUS Healthcare Network Policy in 2010. Within this scope, the Lab for Innovation in Chronic Conditions (LIACC) is a new management tool of PHC based on the Attention to Chronic Conditions Model (ACCM) adapted by Mendes ${ }^{17}$ to be applied in the Brazilian context. The tool was implemented in three cities: Curitiba (2011), Santo Antônio do Monte (2013) and Tauá (2014). The aim of this study is to address the implementation of LIACC in Santo Antônio do Monte (SAMONTE), as well as the main challenges faced by the municipality in the provision of this new chronic condition model. SAMONTE experience was a population-based intervention that involved all providers of primary and secondary care.

Santo Antônio do Monte is a small municipality with around 26,000 inhabitants and located in Minas Gerais, Brazil. It is a high-developed municipality presenting a Municipal Human Development Index of 0.724 in 2010 and infant mortality of 14.8 deaths per 1,000 live births ${ }^{4}$. Most of its population lives in the urban area (85\%), in households provided with good sanitation conditions ${ }^{4}$. In $2012,92 \%$ of its population was covered by eight FHT. Health care supply also included a secondary care facility specialized in care for chronic conditions (Centro Integrado Hiperdia Viva Vida), a specialist dental center, an image diagnostic center, a small hospital (50 beds), and a clinical analysis laboratory.

This study addresses at least two main questions related to the LIACC intervention: what lessons can we learn from this experience and what are the main challenges that should 
be overcome for a more suitable chronic care model at the municipal level? We believe that the SAMONTE experience can be an important opportunity for other municipalities with similar population size and development level.

\section{METHODS}

\section{LIACC in Santo Antônio do Monte}

The conceptual framework of LIACC is the ACCM adapted to the Brazilian context by Mendes $^{17}$. ACCM includes components of the Chronic Care Mode ${ }^{19}$, the Kaiser Pyramid Model $^{20}$ and the Social Model of Health ${ }^{21}$. ACCM proposes seven steps to organize the macroprocesses of PHC (Box 1). LIACC was implemented in SAMONTE as a partnership among the Pan-American Health Organization, the Government of the State of Minas Gerais, the Government of Santo Antônio do Monte, and the National Council of Health Secretaries (CONASS). The information about the LIACC implementation was collected through several technical meetings with Pan-American Health Organization consultants and local staff of SAMONTE who were responsible for the intervention. In addition, we had access to all material used in the workshops to introduce the new tools of primary care to local providers.

The intervention occurred in the municipality between June 2013 and December 2014. It focused on four chronic conditions (pregnant women; children under two years old; individuals with hypertension and diabetes) involving all health professionals of primary and secondary care. This intervention aims to strengthen PHC for chronic conditions by using new tools and protocols developed to manage a longitudinal and integrated network.

The development of LIACC was based on the introduction of the macroprocesses in workshops and a tutoring program delivered by health policy specialists. In each workshop, a schedule of activities and goals were defined for the Health Units (HU) using standard procedures. The tutors developed a set of protocols and clinical guidelines to be followed by PHC providers. A health manager was hired for each HU to guarantee the success of these strategies. They were responsible for articulating all actors of HU, monitoring the use of protocols and clinical guidelines, and managing the process by conducting weekly meetings with FHT.

Steps 1, 2, 3 and 6 in Box 1 were implemented in all HU, while technologies related to the remaining steps were not systematically introduced. The introduction of these steps were

Box 1. The seven steps of the chronic conditions model care (ACCM) and their main macroprocesses.

\begin{tabular}{|c|c|}
\hline Steps & Main macroprocesses \\
\hline $\begin{array}{l}\text { 1. Evaluation of the existing infrastructure and } \\
\text { definition of improvements needed considering } \\
\text { the reference population }\end{array}$ & $\begin{array}{l}\text { Territorialization, registry of families, family risk classification, } \\
\text { risk stratification of chronic conditions. }\end{array}$ \\
\hline 2. Primary care to acute health events & $\begin{array}{l}\text { Patients' reception at Health Unit, Manchester triage system, } \\
\text { delivery of primary care according to Manchester protocol. }\end{array}$ \\
\hline $\begin{array}{l}\text { 3. Primary care to patients with controlled } \\
\text { chronic conditions }\end{array}$ & $\begin{array}{l}\text { Management and monitoring of chronic conditions, risk } \\
\text { stratification of chronic conditions, elaboration of patients } \\
\text { care plan, self-care support. }\end{array}$ \\
\hline $\begin{array}{l}\text { 4. Preventive care and tools to support } \\
\text { behavior change }\end{array}$ & $\begin{array}{l}\text { Physical activities, control of alcohol, tobacco and drugs, and } \\
\text { nutritional re-education groups, motivational interviewing. }\end{array}$ \\
\hline 5. Administrative demands & $\begin{array}{l}\text { Control of medical certificates, renewal of prescription of } \\
\text { drugs and medicines, management of Health Units including } \\
\text { information system, medical records and public health } \\
\text { surveillance. }\end{array}$ \\
\hline 6. Home healthcare & Management and monitoring of household visits. \\
\hline 7. Self-care support & $\begin{array}{l}\text { Self-care training and advice, elaboration of patients care } \\
\text { plan, material support to self-care. }\end{array}$ \\
\hline
\end{tabular}

Source: Mendes ${ }^{17}$. 
conditioned to the ability of health professionals to understand each macroprocess and their engagement with the LIACC goals. Regarding the information system, an electronic record system should be implemented integrating $\mathrm{HU}$ and secondary care providers. However, the municipality did not succeed in reaching this goal.

These innovations were introduced mainly in HU, but also involved the secondary care facility, which allowed the integration of these two health care levels. The macroprocess of territorialization, registry of families, family risk classification, risk stratification of chronic conditions, and the use of the Manchester protocol after a deep change in the organization of PHC. FHT became more aware of the risk and vulnerable conditions of its population, increasing its ability to provide the care needed and reducing unnecessary referrals to secondary care facility. Therefore, the flow of patients between different levels of attention became more coordinated. It is noteworthy that the secondary care facility has already played an important role in providing outpatient care for high-risk patients diagnosed with hypertension, diabetes and women with high-risk pregnancy. It also has provided care to patients living in 12 neighbouring municipalities of SAMONTE. The presence of Centro Hiperdia Viva Vida and its regional importance motivated the choice of SAMONTE for receiving the intervention.

\section{Study Design}

This is an observational case study based on two sources of data. The first source comprises two cross-sectional household surveys conducted in 2013 and 2015. The reference period for each survey was 2012 and 2014, before and during the intervention, respectively. All information was self-reported except for child immunization. In this case, a picture of the child's immunizations card was taken during the interview.

The surveys are representative for the entire population and the target groups: pregnant women; children under two years old; individuals with hypertension and diabetes.

The sample of the entire population is probabilistic at the census sectors level and representative for the population aged between 18 and 65 years with a margin of error equal to $4 \%$. The sample is stratified by HU. Individuals were selected on the basis of quota sampling by age and sex. In total, 596 individuals were interviewed in 2013 and 625 in 2015. Information about household characteristics, socioeconomic status, health status, lifestyle, and health care utilization was collected.

Pregnant women included those who had completed their pregnancy with a live birth between January 2011 and December 2012 (first round of the household survey) and between January 2014 and December 2014 (second round of the household survey). The final sample consisted of 336 pregnant women and their respectively children (183 in 2013 and 155 in 2015), 744 individuals with hypertension (365 in 2013 and 379 in 2015), and 629 individuals with diabetes (312 in 2013 and 317 in 2015). Specific instruments were defined for each target group including information about health status and health care access. Individuals of each target group also answered all questions of the instrument applied to the entire population. The distribution of age and sex for each target group are very similar for both household surveys, which guarantee comparability between both years ${ }^{22}$.

Two groups of outcome variables were selected (Box 2). The first one consists of indicators closely correlated to some macroprocesses of ACCM. The analysis was performed for the macroprocesses that were implemented in SAMONTE and able to be measured by the available sources. The second group includes health outcomes associated with PHC. All indicators are dummy variables equal to one if the attribute was observed, zero otherwise. The only exception is the type of provider for antenatal care (ANC), whose variable has three categories: FHS, other professionals of SUS and private provider. A descriptive statistics analysis was performed based on a comparison of two cross-sections carried out in 2013 and 2015. 
Box 2. Health indicators related to macroprocesses of the ACCM model.

\begin{tabular}{|c|c|c|}
\hline Variable & Definition & Data source \\
\hline \multicolumn{3}{|c|}{ Health indicators related to macroprocesses } \\
\hline Familiar risk classification & $\begin{array}{l}\text { Family risk classification considering social vulnerability, } \\
\text { familiar and individual risk factors }\end{array}$ & Medical records \\
\hline Risk stratification & Risk stratification of patients with diabetes or hypertension & Medical records \\
\hline Registry of families & Enrolment status of the households by FHT & Household survey \\
\hline CHA household visits & $\begin{array}{l}\text { Household was visited by } \mathrm{CHA} \text { at least once in the last } \\
\qquad 12 \text { months }\end{array}$ & Household survey \\
\hline SUS users & Individual usually receive care provided by SUS & Household survey \\
\hline $\begin{array}{l}\text { Private health insurance } \\
\text { coverage }\end{array}$ & Individual has private health insurance coverage & Household survey \\
\hline Diabetes & Individual self-reported having diabetes & Household survey \\
\hline Hypertension & Individual self-reported having hypertension & Household survey \\
\hline \multicolumn{3}{|c|}{ Health outcomes for Individuals with hypertension and diabetes } \\
\hline Doctor visit & $\begin{array}{l}\text { Individual visited a doctor at least once in the last } \\
\qquad 12 \text { months }\end{array}$ & Household survey \\
\hline Doctor visit by SUS & $\begin{array}{l}\text { Individual visited a doctor of SUS at least once in the last } \\
\qquad 12 \text { months }\end{array}$ & Household survey \\
\hline ECG test & $\begin{array}{c}\text { Individual received at least one electrocardiogram test in } \\
\text { the last } 12 \text { months }\end{array}$ & Household survey \\
\hline $\begin{array}{l}\text { Blood test or cholesterol } \\
\text { test }\end{array}$ & $\begin{array}{c}\text { Individual with diabetes did at least one blood test or } \\
\text { Individual with hypertension did at one cholesterol test in } \\
\text { the last } 12 \text { months }\end{array}$ & Household survey \\
\hline \multicolumn{3}{|c|}{ Health outcomes associated with antenatal care (ANC), delivery, and child care } \\
\hline ANC provider & $\begin{array}{c}\text { Main provider of ANC care: FHT, other professionals of } \\
\text { SUS, private }\end{array}$ & Household survey \\
\hline At least 6 ANC visits & Woman received at least 6 ANC visits during pregnancy & Household survey \\
\hline Early prenatal care & Receiving care during the first three months of pregnancy & Household survey \\
\hline Antenatal care tests & $\begin{array}{l}\text { Tests performed during pregnancy: blood test, } \\
\text { toxoplasmosis test, HIV and syphilis test, urine test, oral } \\
\text { glucose test, ultrasound test }\end{array}$ & Household survey \\
\hline Immunization & $\begin{array}{c}\text { Woman was immunized against tetanus and influenza } \\
\text { during pregnancy }\end{array}$ & Household survey \\
\hline Preterm birth & Baby birth before 37 weeks of gestational age & Household survey \\
\hline Vaginal delivery & Baby was born through vaginal delivery & Household survey \\
\hline C-section scheduled & C-section scheduled during the ANC period & Household survey \\
\hline Child immunization & $\begin{array}{c}\text { Child immunization against BCG, hepatitis, poliomyelitis, } \\
\text { DTP, rotavirus, meningitis, MMR }\end{array}$ & Household survey \\
\hline Low birth weight & Birth weight below 2,500 kg & Household survey \\
\hline
\end{tabular}

Source: SAMONTE ${ }^{24}$

FHT: family health teams; CHA: community health agent; SUS: Brazilian Unified Health System; ECG: electrocardiogram; BCG: vaccine against tuberculosis; DTP: vaccine against diphtheria, pertussis, and tetanus; MMR: vaccine against measles, mumps, and rubella

This study meets all ethical requirements involving research with humans established by the 196/96 Resolution of the Ministry of Health. The protocol was submitted and approved by the Research Ethics Committee at the Universidade Federal de São João Del Rei (Process CEP 369.942). The Informed Consent form was read and signed by all interviewees, and a copy was properly filed.

The second source of data comprises medical records of all individuals interviewed in 2013 who had been diagnosed with hypertension or diabetes. We collected information in all HU of SAMONTE for 2012, 2013 and 2014. In this study, three indicators were analyzed: the percentage of medical records identified in the HU, individual risk stratification and family risk classification. 


\section{RESULTS}

Table 1 shows the findings for the entire population, individuals with diabetes and hypertension. In 2012, 95.88\% of the entire population reported that the household was registered in FHS, while $90.94 \%$ reported having received at least one CHA visit during the reference year. In 2014, these percentages were $93.65 \%$ and $95 \%$, respectively. The increase in the coverage of CHA visit between the two years was statistically significant, while the reduction in the FHS coverage was not significant. Besides, more than $90 \%$ of the individuals reported having used public health services. The prevalence of individuals who declared having hypertension remained almost constant over time (26.55\% in 2012 and $27.72 \%$ in 2014), but a significant increase was found in the proportion of those who had diabetes, $4.53 \%$ to $9.44 \%$.

Among individuals with diabetes, the FHS coverage is also universal, around $98 \%$. Additionally, the percentage of those using SUS services and receiving at least one CHA visit in the reference year is quite high, around $98 \%$ and $95 \%$, respectively, remaining stable between both years.

The percentage of individuals with diabetes who visited a doctor during the reference year significantly decreased between 2012 and 2014, from $95.10 \%$ to $89.39 \%$. Among them, 74.23 and $78.78 \%$ received this care through SUS in 2012 and 2014, respectively. Regarding preventive tests, a reduction was found in the coverage of blood test between 2012 and 2014, from $92 \%$ to $89.4 \%$, but it was not significant. The coverage of ECG test remained stable, around $62 \%$.

As for individuals with hypertension, the FHS coverage was also almost universal, around 97\% in both years. Moreover, the percentage of those who received at least one CHA visit in the reference year increased significantly, from $90.08 \%$ in 2012 to $94.97 \%$ in 2014 . In contrast, the percentage of those who declared regular use of SUS services decreased from $98.63 \%$ in 2012 to $96.04 \%$ in 2014. Despite this reduction, the use of public services is too high,

Table 1. Health indicators for the entire population and individuals with hypertension and diabetes before (2012) and during (2014) the LIACC intervention in Santo Antônio do Monte, Brazil.

\begin{tabular}{|c|c|c|c|c|c|c|c|c|c|c|c|c|c|c|c|c|c|}
\hline \multirow{3}{*}{ Variable } & \multicolumn{5}{|c|}{ Entire population } & \multicolumn{6}{|c|}{ Diabetes } & \multicolumn{6}{|c|}{ Hypertension } \\
\hline & \multicolumn{2}{|c|}{2012} & \multicolumn{2}{|c|}{2014} & \multirow{2}{*}{$\underset{(p-v a l u e)}{\chi^{2} \text { test }}$} & \multicolumn{2}{|c|}{2012} & \multicolumn{2}{|c|}{2014} & \multirow{2}{*}{\multicolumn{2}{|c|}{$\begin{array}{c}\chi^{2} \text { test } \\
\text { (p-value) }\end{array}$}} & \multicolumn{2}{|c|}{2012} & \multicolumn{2}{|c|}{2014} & \multirow{2}{*}{\multicolumn{2}{|c|}{$\begin{array}{c}\chi^{2} \text { test } \\
\text { (p-value) }\end{array}$}} \\
\hline & $\mathbf{n}$ & $\%$ & $\mathbf{n}$ & $\%$ & & $\mathbf{n}$ & $\%$ & $\mathbf{n}$ & $\%$ & & & $\mathbf{n}$ & $\%$ & $\mathbf{n}$ & $\%$ & & \\
\hline \multicolumn{18}{|l|}{ Household survey } \\
\hline $\begin{array}{l}\text { Registry of families in } \\
\text { FHS }\end{array}$ & 558 & 95.88 & 575 & 93.65 & 0.085 NS & 305 & 98.71 & 308 & 97.47 & 0.260 & NS & 350 & 97.77 & 364 & 96.55 & 0.324 & NS \\
\hline $\mathrm{CHA}$ household visits & 532 & 90.94 & 588 & 94.99 & 0.006 & 294 & 94.53 & 299 & 94.62 & 0.962 & NS & 327 & 90.08 & 359 & 94.97 & 0.011 & b \\
\hline SUS patients & 554 & 92.95 & 571 & 91.36 & $0.301 \quad N S$ & 310 & 99.36 & 309 & 97.78 & 0.927 & NS & 360 & 98.63 & 364 & 96.04 & 0.029 & b \\
\hline Private health insurance & 184 & 30.87 & 190 & 30.50 & $0.887 \quad N S$ & 107 & 34.41 & 108 & 34.07 & 0.929 & NS & 142 & 38.90 & 146 & 38.52 & 0.915 & NS \\
\hline Diabetes prevalence & 27 & 4.53 & 59 & 9.44 & $0.001 \quad$ a & & & & & & & & & & & & \\
\hline Hypertension prevalence & 158 & 26.55 & 173 & 27.72 & 0.646 NS & & & & & & & & & & & & \\
\hline Doctor visit & & & & & & 291 & 95.10 & 278 & 89.39 & 0.008 & a & 303 & 85.11 & 305 & 81.12 & 0.150 & NS \\
\hline $\begin{array}{l}\text { Doctor visit by SUS } \\
\text { (conditional) }\end{array}$ & & & & & & 216 & 74.23 & 219 & 78.78 & 0.201 & NS & 207 & 68.54 & 199 & 65.25 & 0.3890 & NS \\
\hline ECG test & & & & & & 185 & 61.67 & 195 & 62.30 & 0.872 & NS & 174 & 48.07 & 173 & 45.77 & 0.531 & NS \\
\hline Blood test & & & & & & 276 & 92.00 & 270 & 89.40 & 0.273 & NS & & & & & & \\
\hline Cholesterol test & & & & & & & & & & & & 259 & 71.35 & 281 & 74.73 & 0.300 & NS \\
\hline
\end{tabular}

\section{Source: SAMONTE24.}

LIACC: Lab for Innovation in Chronic Conditions; FHT: family health teams; CHA: community health agent; SUS: Brazilian Unified Health System; ECG: electrocardiogram; NS: not significant;

a Statistically significant at $1 \%$.

b Statistically significant at $5 \%$. 
especially considering that more than $35 \%$ of individuals with hypertension are covered by private health insurance.

More than $80 \%$ of individuals with hypertension reported receiving at least one doctor visit in both years, and more than $65 \%$ of them were treated by SUS. As for the preventive tests, the percentage of people who did at least one cholesterol test is not universal, but the coverage is high, around $75 \%$. For ECG, this number was lower, around $46 \%$. No statistically significant changes were found in the coverage of both tests between 2012 and 2014 .

The analysis of medical records brought positive evidence for the macroprocesses implemented by LIACC. About $84 \%$ and $74 \%$ of individuals who self-reported having diabetes and hypertension were identified in their medical records at $\mathrm{HU}$ diagnosed with the respective condition, besides receiving treatment by FHS. Among them, $80 \%$ of individuals with diabetes and $89 \%$ with hypertension lived in households that had a medical history of family risk classification in their medical records. Most risk classifications were carried out with the LIACC implementation between 2013 and 2015 (71.4\% and 64.7\% of the family risk classification for diabetes and hypertension, respectively). The percentage of individuals with risk stratification record, despite being at low levels, ranges from zero to $35 \%$ and $28 \%$, respectively (Table 2).

Regarding ANC, the coverage is universal (results not shown here), and FHS performs an important role since more than $70 \%$ of women were monitored by this program during their pregnancy (Table 3). In addition, the quality of ANC seems to be satisfactory. Table 3 shows that most women had at least six antenatal visits during pregnancy ( $91.33 \%$ in 2012 and $96.64 \%$ in 2014) and received early prenatal care (85.16\% in 2012 and $94.12 \%$ in 2014). The coverage of both indicators increased between the two years, and this improvement was statistically significant. The coverage of prenatal tests is also almost universal. The exception stands for oral glucose test, whose prevalence is still lower. However, its coverage significantly increased after the LIACC intervention, from 33.33\% in 2012 to $60.78 \%$ in 2014 . Regarding immunization coverage, no significant changes were observed during the period.

Table 2. Family risk classification and individual risk stratification according to the medical records of patients with diabetes and hypertension in SAMONTE.

\begin{tabular}{|c|c|c|c|c|}
\hline \multirow{2}{*}{ Variable } & \multicolumn{2}{|c|}{ Diabetes } & \multicolumn{2}{|c|}{ Hypertension } \\
\hline & $\mathbf{n}$ & $\%$ & $\mathbf{n}$ & $\%$ \\
\hline \multicolumn{5}{|c|}{ Family risk classification in the medical records of the patient } \\
\hline No & 43 & 16.9 & 23 & 8.5 \\
\hline Yes & 203 & 79.9 & 241 & 88.6 \\
\hline Does not know & 8 & 3.2 & 8 & 2.9 \\
\hline Total & 254 & 100 & 272 & 100 \\
\hline \multicolumn{5}{|c|}{ The most recent year of family risk classification } \\
\hline 2009 & 9 & 4.4 & 10 & 4.2 \\
\hline 2010 & 3 & 1.5 & 2 & 0.8 \\
\hline 2011 & 0 & 0.0 & 2 & 0.8 \\
\hline 2012 & 2 & 1.0 & 2 & 0.8 \\
\hline 2013 & 87 & 42.9 & 68 & 28.2 \\
\hline 2014 & 52 & 25.6 & 69 & 28.6 \\
\hline 2015 & 6 & 3.0 & 19 & 7.9 \\
\hline No record of the year & 44 & 21.7 & 69 & 28.6 \\
\hline Total & 203 & 100 & 241 & 100 \\
\hline \multicolumn{5}{|c|}{ Individual risk stratification in the medical records of the patient } \\
\hline No & 166 & 65.35 & 195 & 71.7 \\
\hline Yes & 88 & 34.65 & 77 & 28.3 \\
\hline Total & 254 & 100 & 272 & 100 \\
\hline
\end{tabular}

Source: SAMONTE ${ }^{24}$. 
In 2012 , about $77.60 \%$ and $90.71 \%$ of pregnant women were immunized against influenza and tetanus, respectively. In 2014, these figures were $75.16 \%$ and $91.50 \%$. Despite the outcomes observed for ANC, childbirth characteristics did not present a good performance. Only $21 \%$ of women had vaginal delivery. Besides, almost $11 \%$ had low-birth-weight infants and around $27 \%$ had a preterm birth. These indicators showed little variability over time, except for the pre-schedule C-section births that decreased from $65.28 \%$ to $50.82 \%$ (Table 3 ). Figures for child immunization showed universal coverage for all children aged between $0-2$ years (Table 3 ).

Table 3. Antenatal care, delivery and child immunization according to vaccination card before (2012) and during (2014) the LIACC intervention in Santo Antônio do Monte, Brazil.

\begin{tabular}{|c|c|c|c|c|c|c|}
\hline \multirow{2}{*}{ Variable } & \multicolumn{2}{|c|}{2012} & \multicolumn{2}{|c|}{2014} & \multirow{2}{*}{\multicolumn{2}{|c|}{$\chi^{2}$ test (p-value) }} \\
\hline & $\mathbf{n}$ & $\%$ & $\mathbf{n}$ & $\%$ & & \\
\hline \multicolumn{7}{|c|}{ Antenatal care and delivery } \\
\hline \multicolumn{7}{|l|}{ ANC provider } \\
\hline FHT & 130 & 72.63 & 114 & 75.00 & 0.132 & NS \\
\hline Other professionals of SUS & 11 & 6.15 & 3 & 1.97 & & \\
\hline Private & 38 & 21.23 & 35 & 23.03 & & \\
\hline At least 6 ANC visits, since she did the ANC & 158 & 91.33 & 144 & 96.64 & 0.049 & b \\
\hline Early prenatal care, since she did the ANC & 156 & 85.16 & 144 & 94.12 & 0.008 & a \\
\hline \multicolumn{7}{|l|}{ Antenatal care tests } \\
\hline Blood test & 180 & 98.36 & 153 & 100.00 & 0.112 & NS \\
\hline Toxoplasmosis test & 150 & 81.97 & 138 & 90.20 & 0.061 & NS \\
\hline Urine test & 178 & 97.27 & 153 & 100.00 & 0.039 & b \\
\hline HIV and syphilis test & 167 & 91.26 & 146 & 95.42 & 0.284 & NS \\
\hline Oral glucose test & 61 & 33.33 & 93 & 60.78 & 0.000 & a \\
\hline Ultrasound test & 182 & 99.45 & 153 & 100.00 & 0.360 & NS \\
\hline \multicolumn{7}{|l|}{ Immunization } \\
\hline Immunized against influenza & 142 & 77.60 & 115 & 75.16 & 0.601 & NS \\
\hline Immunized against tetanus & 166 & 90.71 & 140 & 91.50 & 0.765 & NS \\
\hline Preterm birth & 48 & 26.23 & 42 & 27.45 & 0.527 & NS \\
\hline Vaginal delivery & 39 & 21.31 & 31 & 20.26 & 0.813 & NS \\
\hline $\begin{array}{l}\text { C-section scheduled, since the delivery was a } \\
\text { c-section }\end{array}$ & 94 & 65.28 & 62 & 50.82 & 0.017 & b \\
\hline Low birth weight & 21 & 11.67 & 17 & 10.97 & 0.841 & NS \\
\hline \multicolumn{7}{|c|}{ Child immunization according to the vaccination card } \\
\hline BCG & 157 & 100.00 & 131 & 100.00 & & \\
\hline Hepatitis B (HepB) & 158 & 99.37 & 130 & 99.24 & 0.891 & NS \\
\hline Oral polio vaccine (OPV) & 158 & 100.00 & 121 & 100.00 & & \\
\hline DTP & 159 & 100.00 & 120 & 99.17 & 0.278 & NS \\
\hline Rotavirus & 157 & 99.37 & 120 & 100.00 & 0.372 & NS \\
\hline Pneumococcal & 157 & 100.00 & 119 & 100.00 & & \\
\hline Meningococcal & 159 & 100.00 & 119 & 100.00 & & \\
\hline MMR & 129 & 98.47 & 23 & 100.00 & 0.244 & NS \\
\hline Yellow fever & 137 & 100.00 & 27 & 100.00 & & \\
\hline
\end{tabular}

Source: SAMONTE ${ }^{24}$.

LIACC: Lab for Innovation in Chronic Conditions; ANC: antenatal care; FHT: family health teams; SUS: Brazilian Unified Health System; BCG: vaccine against tuberculosis; DTP: vaccine against diphtheria, pertussis, and tetanus; MMR: vaccine against measles, mumps, and rubella. The vaccine coverage was calculated based on the number of eligible children for each vaccine according to the children's age; NS: not significant

a Statistically significant at $1 \%$.

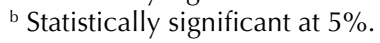




\section{DISCUSSION}

The case study of SAMONTE raises some challenges and lessons that clarify future interventions on building a PHC network. The first lesson is the importance of SUS as the main provider of primary care in small municipalities. According to our findings, the FHS coverage in SAMONTE was universal even considering the high coverage of private health insurance. The importance of FHS was already noticeable before the intervention, since almost $100 \%$ of the households were registered in FHS and $91 \%$ received CHA visits. These figures are even higher than the coverage observed in Brazil. In 2013, 63\% of the households in the country were registered in FHS and about $83 \%$ declared receiving at least one $\mathrm{CHA}$ visit ${ }^{23}$.

The second lesson shows the importance in establishing a PHC network in small municipalities. According to the health professionals of SAMONTE, the profile of refereed patients changed after LIACC. The implementation of macroprocess, mainly the individual risk stratification, empowered FHT to screen patients to receive treatment at different levels of care, since this strategy was not implemented in SAMONTE before LIACC. The coverage of individual risk stratification increased from zero to $35 \%$ and $28 \%$ for patients with diabetes and hypertension, respectively. As expected, the risk stratification is usually gradually implemented, since this process depends on diagnostic tests. The increase in the prevalence of the self-reported diabetes from $4.53 \%$ in 2012 to $9.44 \%$ in 2014 also corroborates that FHT became more aware of the population's risk conditions.

The third lesson reinforces the role of $\mathrm{CHA}$ and of the health managers of $\mathrm{HU}$ as fundamental actors in the PHC network. CHA are responsible for the visit and registry of the households, as well as for the implementation of the risk classification and stratification. The coverage of CHA visits was already universal for all target groups before LIACC, but these macroprocesses were not fully achieved. The individual risk classification had never been implemented before LIACC, while the family risk classification was carried out only once, but it was not regularly monitored and updated. The health managers, introduced by LIACC, are in charge of monitoring CHA to ensure the full implementation of these macroprocesses.

Despite these results, the implementation of LIACC posed some challenges that need to be overcome in future experiences. At first, the SAMONTE experience did not consider reorganizing the supply of diagnostic tests. This issue is important to be addressed, since LIACC did not succeed in providing universal coverage of preventive tests defined by the protocols for patients with diabetes and hypertension. Besides, as the Brazilian Health System is mixed, some individuals have dual access to healthcare services. For instance, they can visit a doctor in the private sector and receive the diagnostic tests from the public sector. This dual system allows individuals to bypass the procedures established in the public PHC network and prevent the adequate management of the supply of diagnostic tests.

Another challenge is the use and implementation of an electronic system in small municipalities. This tool is important to improve the quality of clinical records, to allow the integration of all health care units (PHC and specialized units), and to ensure the management of a longitudinal care. In SAMONTE, the electronic system should have been introduced with LIACC. However, this macroprocess was not implemented because it involves decisions and resources at Federal and State levels. Even though the computers were provided by State Health Secretary during LIACC, their use requires the development of a suitable software, the training of health professionals and adequate internet connection.

Finally, SAMONTE is a pilot experience and the scale up of ACCM is not trivial. SAMONTE was chosen to receive this intervention due to the presence of a well-organized secondary facility that has already provided a good care to the target groups compared with other municipalities. Besides, LIACC is a complex intervention. It comprises the incorporation of different tools in health care management, which involves all health professionals and their ability to understand this new management of chronic conditions. In SAMONTE, this 
caveat became evident when some of the health managers were dismissed due to labor regulation of the public sector in Brazil.

We believe this study is the first opportunity to address the implementation of an ACCM in a small municipality in Brazil, contributing thus to future experiences. The increase in the prevalence of chronic conditions is a reality that should be faced by low- and middle-income countries that are still consolidating a healthcare system able to tackle population needs. The PHC network is essential to provide an adequate and longitudinal care, considering the population's aging scenario.

\section{REFERENCES}

1. Victora CG, Barreto ML, Leal MC, Monteiro CA, Schmidt MI, Paim J, et al. Health conditions and health-policy innovations in Brazil: the way forward. Lancet. 2011;377(9782):2042-53. https://doi.org/10.1016/S0140-6736(11)60055-X

2. Paim J, Travassos C, Almeida C, Bahia L, Macinko J. The Brazilian health system: history, advances, and challenges. Lancet. 2011;377(9779):1778-97. https://doi.org/10.1016/S0140-6736(11)60054-8

3. Medici A. Propostas para melhorar a cobertura, a eficiência e a qualidade no setor saúde. In: Bacha EL, Schwartzman S, organizadores. Brasil: a nova agenda social. Rio de Janeiro: Instituto de Estudos de Política Econômica; Casa das Garças; 2011. p. 23-93.

4. Programa das Nações Unidas para o Desenvolvimento; Fundação João Pinheiro; Instituto de Pesquisa Econômica Aplicada. Atlas do Desenvolvimento Humano no Brasil. Brasília, DF: PNUD; FJP; IPEA; 2013 [cited 2016 Sept 20]. Available from: www.atlasbrasil.org.br/2013

5. Fuhrmann NL. 19. Programa Saúde da Família: viabilizando a saúde pública universalizada no Brasil. Textos Contextos (Porto Alegre). 2003 [cited 2016 Sept 20];2(2):1-15. Available from: http://revistaseletronicas.pucrs.br/ojs/index.php/fass/article/viewFile/966/746

6. Lentsck MH, Kluthcovsky ACGC, Kluthcovsky FA. [Evaluation of the Family Health Program: a review]. Cienc Saude Coletiva. 2010;15 Suppl 3:3455-66. Portuguese. https://doi.org/10.1590/S1413-81232010000900020

7. Ministério da Saúde (BR). Política Nacional de Atenção Básica. Brasília, DF; 2006.

8. Brandão JRM, Gianini RJ, Novaes HMD, Goldbaum M. The family health system: analysis of a health survey in Sao Paulo, Brazil. J Epidemiol Community Health. 2011;65(6):483-90. https://doi.org/10.1136/jech.2008.077172

9. Conill EM. [A historical and conceptual model for Primary Health Care: challenges for the organization of primary care and the Family Health Strategy in large Brazilian cities]. Cad Saude Publica. 2008;24 Suppl 1:S7-16. Portuguese. https://doi.org/10.1590/S0102-311X2008001300002

10. Fertonani HP, Pires DEP, Biff D, Scherer MDA. The health care model: concepts and challenges for primary health care in Brazil. Cienc Saude Coletiva. 2015;20(6):1869-78. https://doi.org/10.1590/1413-81232015206.13272014

11. Couttolenc B, Dmytraczenko T. Brazil's primary care strategy. Washington, DC: World Bank; 2013.

12. Andrade MV, Noronha K, Barbosa AC, Silva N, Rocha T, Arantes R, et al. Equidade na saúde: o Programa de Saúde da Família em Minas Gerais. Belo Horizonte: Autêntica Editora; 2013.

13. Porto SM, Ugá MAD, Moreira RS. Uma análise da utilização de serviços de saúde por sistema de financiamento: Brasil 1998-2008. Cienc Saude Coletiva. 2011;16(9):3795-806. https://doi.org/10.1590/S1413-81232011001000015

14. Escorel S, Giovanella L, Mendonça MHM, Senna MCM. [The Family Health Program and the construction of a new model for primary care in Brazil]. Rev Panam Salud Publica. 2007;21(2-3):164-76. Portuguese.

15. Schmidt MI, Duncan BB, Azevedo e Silva G, Menezes AM, Monteiro CA, Barreto SM, et al. Chronic non-communicable diseases in Brazil: burden and current challenges. Lancet. 2011;377(9781):1949-61. https://doi.org/10.1016/S0140-6736(11)60135-9

16. World Health Organization. Innovative care for chronic conditions: building blocks for actions: global report. Geneva: WHO; 2002. 
17. Mendes EV. As redes de atenção à saúde. Brasília, DF: Organização Pan-Americana da Saúde; 2011.

18. Organização Mundial da Saúde. Cuidados inovadores para condições crônicas: componentes estruturais de ação: relatório mundial. Genebra: OMS; 2003.

19. Wagner EH. Chronic disease management: what will it take to improve care for chronic illness? Eff Clin Pract. 1998;1(1):2-4.

20. Porter M, Kellog M. Kaiser Permanente: an integrated health care experience. Rev Innov Sanit Aten Integr. 2008;1(1):1-8.

21. Dahlgren G, Whitehead M. Policies and strategies to promote social equity in health. Stockholm: Institute for Future Studies; 1991.

22. Andrade MV, Noronha K, Cardoso C, Lorenzi C, Rodrigues CM, Calazans JA, et al. Avaliação do laboratório de inovações no cuidado das condições crônicas na atenção primária à saúde de Santo Antônio do Monte. Belo Horizonte, MG: Centro de Desenvolvimento e Planejamento Regional da Universidade Federal de Minas Gerais - CEDEPLAR; 2017. (Texto para discussão; n. 552).

23. Instituto Brasileiro de Geografia e Estatística. Pesquisa Nacional de Saúde 2013. Rio de Janeiro: IBGE; 2013 [cited 2016 Sept 20]. Available from: http://www.ibge.gov.br/home/estatistica/ populacao/pns/2013/

24. SAMONTE. Pesquisa realizada no município de Santo Antônio do Monte, 2013 e 2015 no âmbito do projeto de Avaliação do Laboratório de Inovação às Condições Crônicas. Belo Horizonte: Centro de Desenvolvimento e Planejamento Regional da U̧niversidade Federal de Minas Gerais - CEDEPLAR; 2015

Funding: Pan American Health Organization (PAHO), Carta Acordo PAHO - IPEAD/FACE/UFMG BR/ LOA/1400085.001, Conselho Nacional de Secretários de Saúde (CONASS), and Fapemig Edital 14/2013 Pesquisa para o SUS CSA - APQ-03559-13.

Authors' Contribution: Design and planning of the study: MVA, KN, CSC, CDLO. Data collection, analysis, and interpretation: MVA, KN, CSC, CDLO, JC, MNS. Preparation or review of the study: MVA, KN, CSC, CDLO, JC, MNS. Approval of the final version: MVA, KN, CSC, CDLO, JC, MNS. Public responsibility for the content of the article: MVA, KN.

Conflict of Interest: The authors declare no conflict of interest. 